\title{
LA CENICIENTA DEL DERECHO CIVIL: LA PROMESA DE PAGO Y EL
}

\section{RECONOCIMIENTO DE DEUDA}

\author{
Hener Hunwco Piscocht
}

\author{
Abezade par ti Linaritad Neciond Mapor de San Marees.

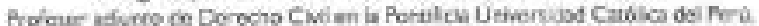

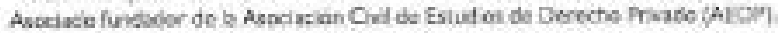 \\ "(...) pocos institutas eszdín dienas de tanto asavidad y generon \\ tontes dudas como ies promesas wallaterakes." \\ Carlo Alberto Grazani, en "Le promease unilaterdi"
}

\section{Sumano:}

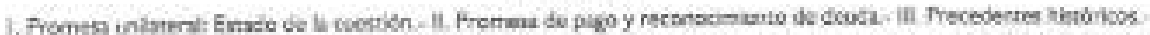

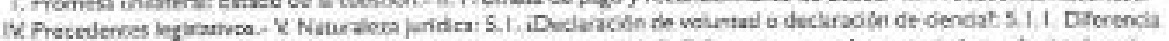

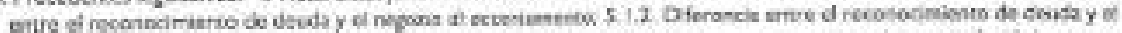

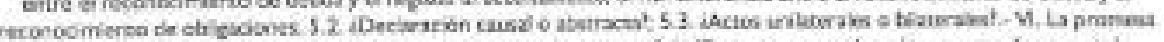

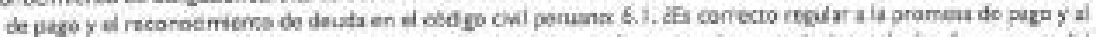

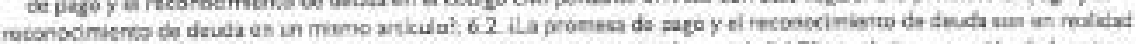

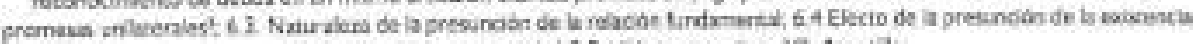

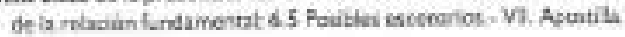

\section{PROMESA UNILATERAL: ESTADO DE LA CUESTIÓN}

Hubo una vez ura jowen muy bells que no tenia padres, sino une madrastra, que era una viuda impertinente con des hijas feas y malvadas. Esta jover hacia los trabajos más duros de la casa y come sus vestides estaban siempre tan manchados de ceriza, todos la larnaban Cenieienta. Un dia el Rey de aquel pa's anunció que iba a dar una gran fiesta a la que inmtaba a tedas las jóvenes casaderas del raino. Ta Cevicienta, no irds - dipo la madrastra-. Te quedaris en casa freqando el suelo x preparando la cena para cuando volvamos. Llegó el dla del bale y Cenicienta apesadumbrada vio partir a sur hermanastras hacia el Palsco Real. Cusnde se encontró sola en la cocina no pudo reprimir sus sclozos, exclarrarido: ipor qué seré tan desgraciada? (...)

En el Derecho Civil peruano existe un instituto que pidece las mismas penurias de exclusión y marginación que tuvo La Cenicienta. Este ingtituto es la promesa un lateral. En ofecto, en auestro medio no existen (ni ea libros ni en revistas juridieas) trabajos destinados al estudio de b promesa unilateral. Es más, ni siquiera, los comantarios exogéricos del Cdidigo CMl, tales como "Exégesis" de Max Arias Schereiber y la importante colección de la Biblioteca Para Leer el Código Civil de la Pontificia Universidad Católica del Perú han comentado los articulas referentes a la promesa urilateral. Asimamo, los pocos trabajos que se refleren a ella pecan de graves imprecisiones. Ael, por ejemplo, algunos autores fa consideran un contrato', otros sonjalan que la promess uniateral genera ebligaciones, pero soguidamente afirman que la obligacion surge con la aceptación tácita o expresa del destinatar ist. ocros, finalmente, la desarrollan bajo el titulo Modificaciones sugeridas

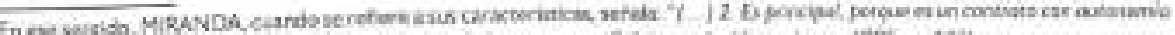

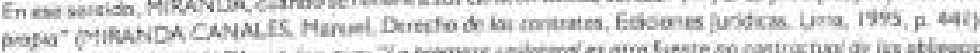

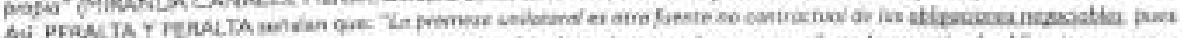

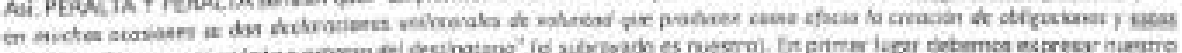

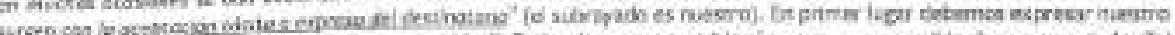

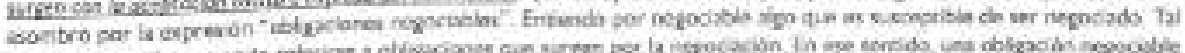

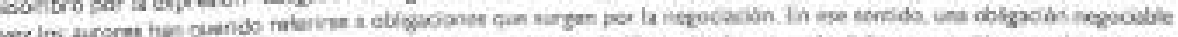

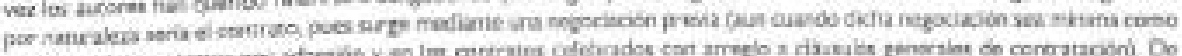

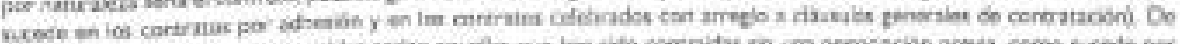

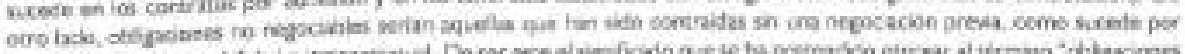

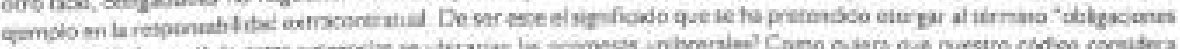

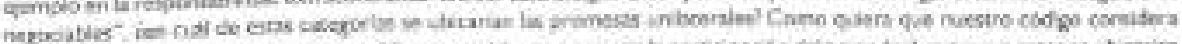

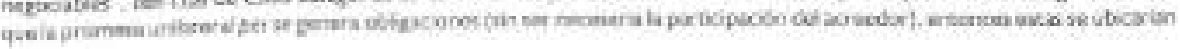


af libro de los Cantrates Namingados, de donde se infiere que se la considera como un contrato nominado?

Sin embargo, esta sinuación de indiferenta no solo es mostrada por la doctrina racional, sino tambièn per nuestra judicarura. En electo, en nuestro medio, es escasa la jurisprudenciz que existe sabre la promesa unilsteral. Ello, a nuestro paraces, puede cbedecer a las sguientes dos razones: (1) en un institute miy eficiente, ws decir, no existen incumplimientos de promesas unilarerales fpor evo no scuden ai Padar Judiciaf): o (ii) los procesos que han versado sobre promesza unlarerales culminaron en instancias inferionas, ya sea porque las partes han estado de acuerdo con la sentencia de primere instancia, 0 ; ainque no lo hayan eatado, la cuantia de la pratension (mirimas por lo geveral cuando se tratan de promesas ordinarias), no haya justificado ir a una instancia superice."

Finalmente, el desintecis en al exudio de la "Cenicienta del Derecho civil" también se puede apreciar en las planos de estudio de las focultades de Derecho do las distintas uriversidades de nuestro pais en las que no existe un curso dadicado (ni siquiera como un capitulo) a la promesa unilateral. Es mis, asi como sucede en el cuerto, tampoco so la invita a participar en les fiestas (conferencias 0 seminarios).

\section{PROMESA DE PAGO Y RECONOCIMIENTO DE DEUDA}

Habiendo conocido grasso modo ol escenario en el que desenvuehve en nuestro medio in promesa unilateral, a continuación vamos a estudiar dos de s.1s feonsidaradas por nuestro Código Civil especies: la promesa de pago y el reconocimiento de deuda. Sin embargo, debemos actuertir a) lector que el presente articulo no pretende arr bar a conclusones corteras e imelutables, sino por el eomtrario, solo conscituir el punto de partida del estudio do un instituto que, camo hervos senalado, na ha sido estudiado en nuestro pais.

La promosa de pago y el feconocimiento de deuca son meplados por al articulo 1959 del Codigo Civil, en los siguientès terminos: "La persono en favar de la cual se hince par declaracilen ursiateral une promess de pono o un reconocimiento de réeuda, queda dispensada de probor la reicción findamerital, cuyo existencia se presume" "Iterpretando de manara literal este articulo tenemos que por la simple promesa de pago o ef reconocimienso de deuda que efectúe una persona a favor ce cera, sa prosume que existe una relación juridica (causal o fundamertal) entre elias, en consecuencia, el destinatario de la declaracián se corviarto on acrendor, mientras qua el autor de la misma, en deudor.

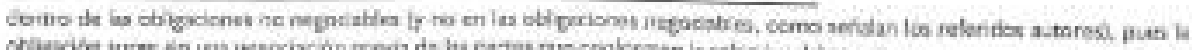

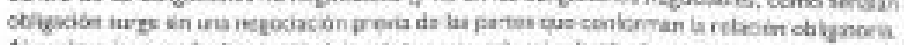

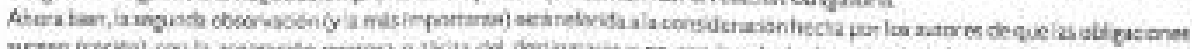

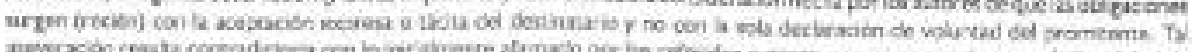

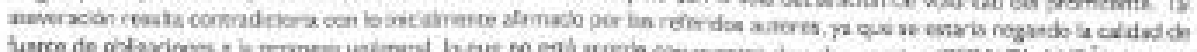

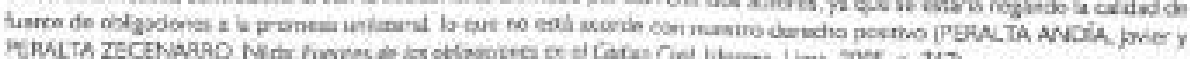

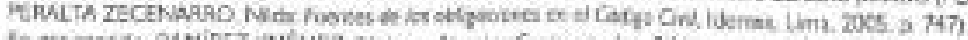

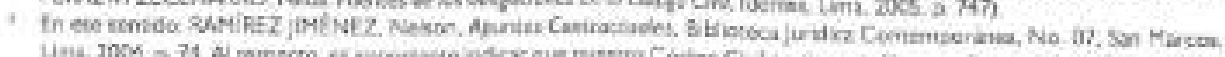

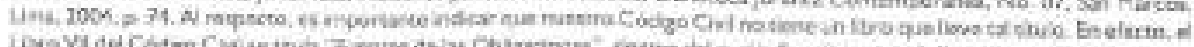

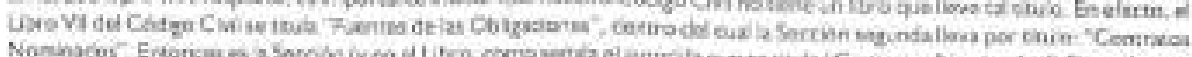

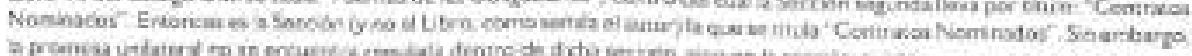

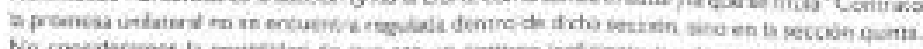

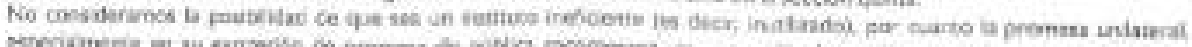

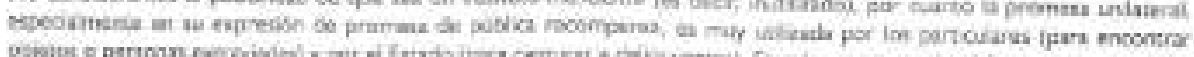

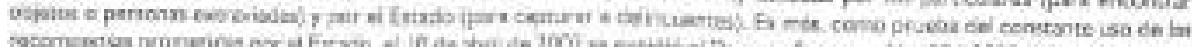

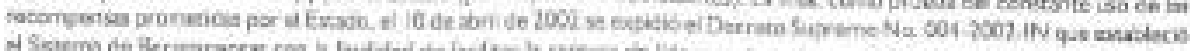

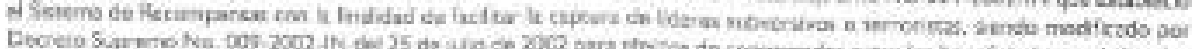

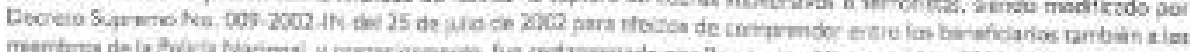

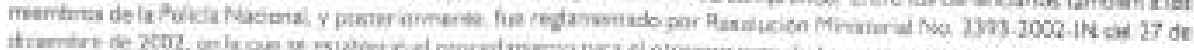

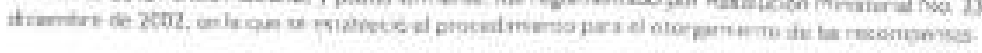


No obstarna lo senollo que resula electuar una interpretakión literal del articulo 1958 dol Cóchige Cint, tes dectarasiones contenidas en este articulo han sido iy son, inelesive en b actualdadj objece de un intoresante debate on la doctrina comparada. Para efoctos de incorporamos en este debate, vemos a establocer previamente un arden en el exquerta del presente artiklo. En primer lygar, analizaremos los

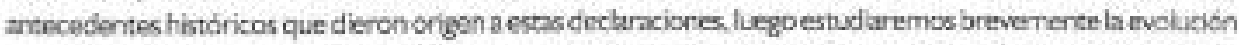

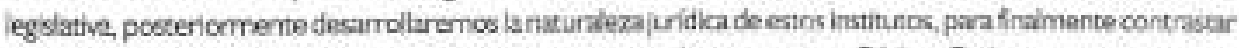

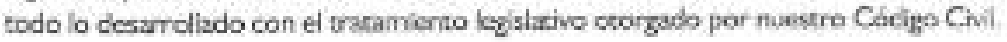

\section{PRECEDENTES HISTÓRICOS}

Intentando encontrar un fundamenta histórico y lógico del contenido de estas declaraciones, podemos seivalar que desde antiguo se ha protendido crear una herramienta lega que oxorgue ofectos juridicos a la sola declaración que realice un deudor medianta la cual reconozca ser deudor o prometa el pago de su ceuda. Se pretendia, ademis, que esta declaración tengz el electo de liberar al acroedor de la carga do probar su situación juridica acreedora y asi, pueda satisfacer mis fácilmente su derecho crécito. Para que se produxea tal efocto, no debia requerirse la intervención dal acreedor, sino debía ser suficiente la doclaración del deudor. Corroborando esta sltuacion, Grazani seffala que: "(..) como demuestran los aumerosos documentos medievales que contenion constituta, recepta, cautiones, promesus, confesiones, que ban ilegado hasto lo octumidad desde siempre fa prodictice ha advertido la exigencio de garantizar, desde el punto de visto procesd, el cumplimiento de abligacianes volidamente existentes: en taies escricos, generaimente notariales, el doudor canfiesc tener unis derte

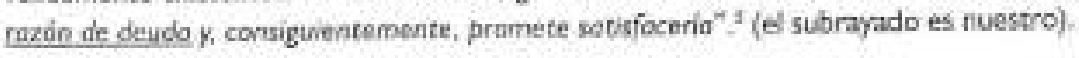

En un inicio se exigin que los instrumentos par los cuales el deuder extericrizaba su veluntad indiquen expresamente ef origen de la deuda que nstabs siendo reconocida $\varphi$ cuyo pego se estaba prometiendo. Dicha exogencia $-z$ decir de Behr-se debia en primer lugar a que se pensaba que el documento que no indicaba la causa impedia el conocimiento de ta causa subyacente. En sequndo lugar, se debia señalar la causa para posibilitar su impugnación. En tercer luzar, existia el peligro para el deudor de terar que pagar dos veces, porque podria ser demandado indistintamente par al documento que no expresa la causa y por el contrazo subyacente, Y por último, existia la posibilidad de que la causa subysconte ses iliciza, impidiendo asi cl control juticial, lo que constituye ta razón fundamental para descomfiar de este tipo de declaraciones."

Sin embargo, con el transcurrir del tiempo, la exigencia de expresar la causa de ì deuda desapareció, siendo vijidas tales declaraciones con la sola manifestacion de ser deudor. Asi, Graziani nos relath que "Hosta fo juristrudendia de los pariamentes fronceses de fines del sigho XVI, tries declaracianes deblan contener ib expressio causoe. es decir, debian ser titubdas, esto es, indicar la razón de la deuda. Sucesivomente. a través de la proctaco conercial froncewo de las bifiets nan causés (precisamente las prameses dacumentaies que no mencionden la cousa de lo devido, y esto es, declorociones del tipa je

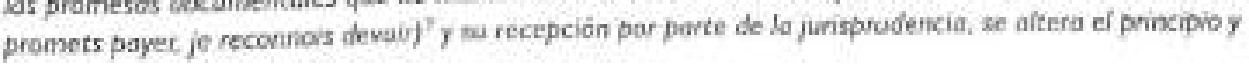

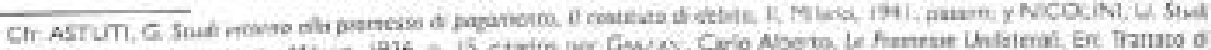

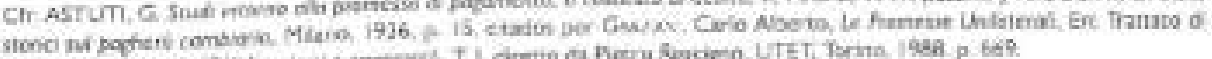

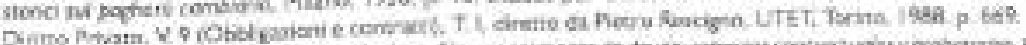

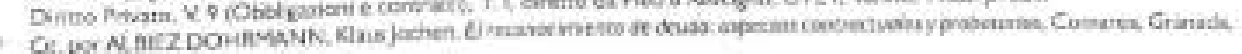
$1587,212$.

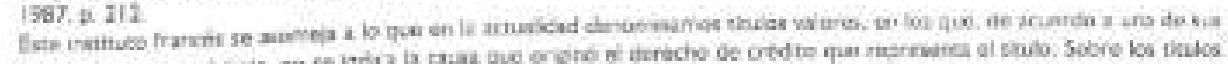

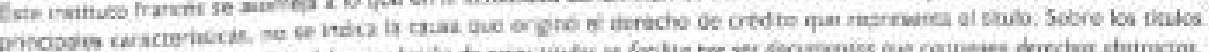

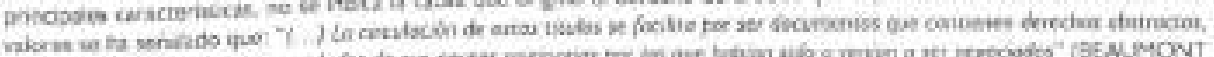

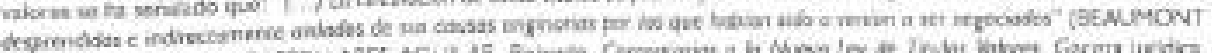

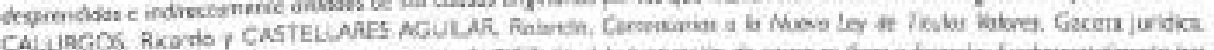

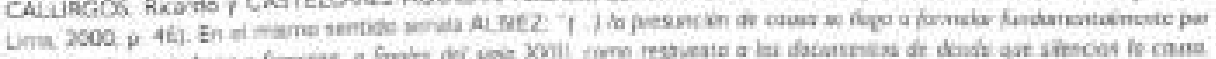

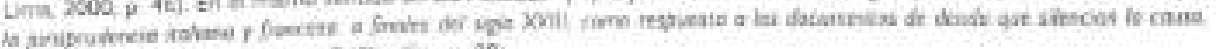

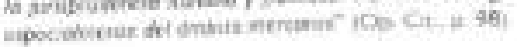




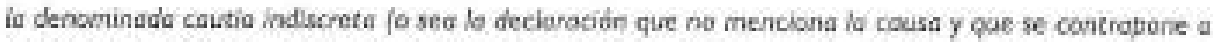
io coutio discreto) comenas a marcar profindamente io experiencie juridica franca-italiang hosta entrar en las relativas codficceciones". "Tal stuación indujo a los legisladores de la época a incluir una aorma que roconozca esta situación de hecho, estableciendo una presunción de la causa. Asi, por ejemplo,

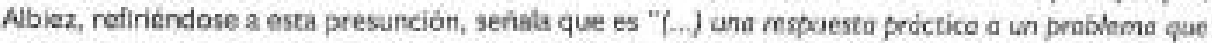
constontenente surgio onte les tribuncies:-formuländase la siguiente preginto- ique eficocio tiene un docamento que na indite la cousd?

E5, entonees, bs prictica comereial, en buena cuenta, la que exigió un reconocimiento positivo de la promesa de page y del recenecimiente de deuda que no expresabar la cusa. A continuación vamos a conocer la forma en que los legisbadores de esa Época afrontaron esta práctica que, con ol amarzar del tompo, se iba gentralizanda.

\section{PRECEDENTES LEGISLATIVOS}

El primer cuerpo normativo en establecer la presunción de la causa fue el Code Napoleón, que, en su articulo | 132, schala. "Lo convention n'est pos meirs valable, quaique lo couse n" en sois pas exprimée", es decir, "la convenciún no es menos por mús que la cousu no seu expresoda en ello". Plefiriéndose a este artícuio, Capitant sendó que los legisladores franceses: "(..) odoptaron purc y simpiemente is reluciän que habio triurfodo en la jurisprudencio, y la expresaron en una förmulo que no se preste a ninguna equathococión". ${ }^{10}$

Posteriormente, e Código Civil italimo de 1865, en sus artículos $1 / 20$ y 112 | regularan situaciones similares, secialentio que "El controto es vajido aunque no se exprese la couso" y "lo caurd se presune mientros no se pruebe io contrario", mespextivamente; las euales -a decir de Graxistil codificas el fenómeno de la larrada abstracción procesal de la causa y representan el precedente inmediato del articulo 1988 del Código civil isaliano de 1942 (que a su vez, es el antacedente directo del arricuio 1958 del Cód go civil pervano).

Repárese hasta aqui la diferencia que excste entre la causa del contrata fes decir, de la relación causal o fundamental) y la causs del reconocimento de deuda o de la promesa de pago, Graciari, comentando el articula I 120 del Código Covil italano de 1865, servala que esce articula "(...) preve lo hipotesis de ousenicia de expresión de la causa: Ella, por tanto, no se refiere ol controta, sino a la declaroción (de segundo grado) que declara su existencie. Entonces, ef articulo deberla ser leida en estes tinninos: "el cantrato ex volido, aunque lo jecloroción que la deciara no exprese la causo", añadiendo más adelante que "deciarar el contrato sin enweiar la cause quere decir declarar ía existencia de uno abligución cantroctual sin mencianar la fuente, esto es, el especifico hecho cantitutivo" "La declaración de roconocimiecto, entonces, constituyo una declaración que no forma parte de la celebración del contraro (que dio orizan a la relación fundamental), sino as una doclaración posterior (de segundo grado) que sirve, justamente, para reconocer ta relación fundernental, cuya esiatencia se presume aj ser reconocida.

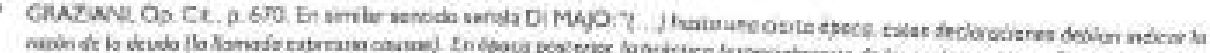

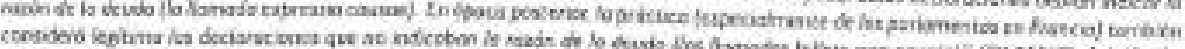

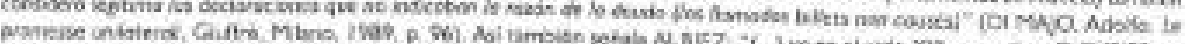

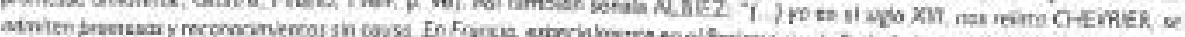

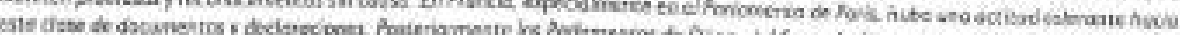

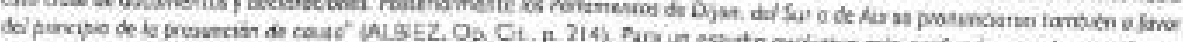

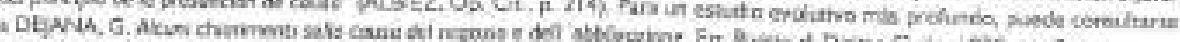

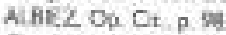

C CE por ALEEZ Op Cir. p $3 / 4$

GRAZIAW, Os, Cf, $\mathrm{n} \in \mathrm{ET}$

Bumn, o 67
} 


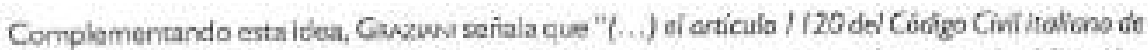

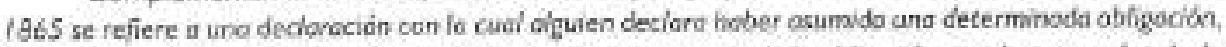
y. por cansigulente, reconoce ser deudar sin mencionar la causa de il obligoción; por io tonto, el articulo 1120 debe ser leida ast' "B reconocimiento de deuda es wibido aumque no exprese la cousa de io decoda" Finoliza el citado outor italiano precisando io que se debe entender por couss: "( . . ) no más razón dél cartrato. sino fuente, esto es, heche constitutino de iv obifgeción: causo ex quo nexcitur, no significa causa

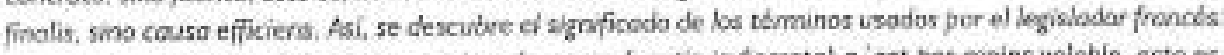
el recanocimienta, tambièn si na menciona fa tausa (coutio indiscreta) n est par moins walahie, esto es

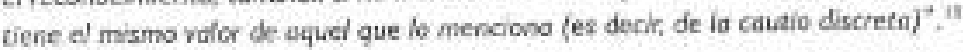

Tenemos entonces que tanco el Code come ef Codice (de 1865) consideraban valido of reconocimiento de deuda aun s' en el mismo no se haya hecho expresa referencis al hecho conssiturivo de la obligación. Como era de esporarse, esta corrierte llegó a Alemania, en dande el logislador de 1900 inclisyó en el Título Veinte del BGB, denominado "Schuldrersprecher" (Promesa de deuxa) y "Schuidonerbenntriss" (Reconocimienco de deuda) las siguienses normas: par. 760: "Poro fo validez de un conerato par ei cual cs prometida une prestación de formo que ic promesc debe originar en vi miamo to ablizocien (promeso de deudo)"t, es necesmo, en tanto no este prescrita otra forma, otarganiento escrito de io promesa", gar. 78 I: "Paro la validez de un cantrato por el cual es reconocido la existencia de una relacián abligutoria (recanocimiento de dewda) ${ }^{15}$ es necesaris otargorniento escrito de la decianoción de recanacimento. Si está presserita otro formo para el arigen de la relacién oblizotorio cujo existencid es reccriacida, requiere esta formo ed cantrato de recanocimiento": Y par. 782; "Si una pramesa de deuda o un reconocimiento de douda son otargados en bese a ura biquidoción o por vía de fa transacrián, la abservincie de la formo escrita trescrita en las pardzrefos 780 y 781 no es necesaria"

De la lectura de las normas trascritas del Code, Codce y BGB notamos que tales cuerpos normativos le restaron importancia a la rranifestación expresa de la causa, pues aun en el caso de que no se expresara, se presumla su existencla. Adernis, la abstrakción de la causz se roguló do manera geverai para todos los contratos \{a excepción del BGB, que solo se refiere a la promesa de paga $y$ al reconocimiarto de decuta).

Postericrmente, con la entrada en vigencia del Codice de 1942, esta cuerpo normativo redujo ef imbito de aplicación de la presunción de la causa al raconocimiento de deuda y a la promesa de pago, conforme lo dispone el articula 1989: 'La promesa de pogo y el reconocímiento de una deudo dispenso o aquel. e favar del cail se hace, de is carga de probar la rehación findamental. Le existencia de este se presume sialvo pruebe en cantrario". La reducción del ámbito de aplicación - següi Albieztiene sna explicación légica, jues la mazifestación max tipica de los cortratos que no expresan la causa son al recanocimiemo de deuja y la promesa de pago, "Además, la sustitución del término "causa" por el de "rebación fundamertal"-a decir de Lenner-es una expresión torrada de la doctrina dek derecho cambiario." En general, of logislador italiano de 1942 opto por: (i) ubicar a ambas declarzcianes dentro del Titulo reforido a las promeses unilaterales, (ii) agruparias a ambos en un msmo articula, y (iii) otorgarles los mismos efectos, fiv) lo que ha generado numerosas criticas de parte de la doctrina itziliana.

Veamos lo que dispone nuesiro articilo 1958 para advertic bo sorprendonte sirvilitud que tiere

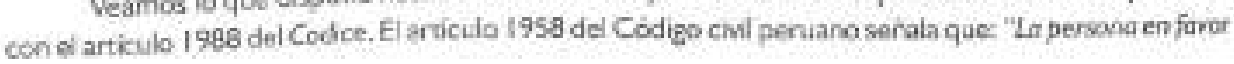

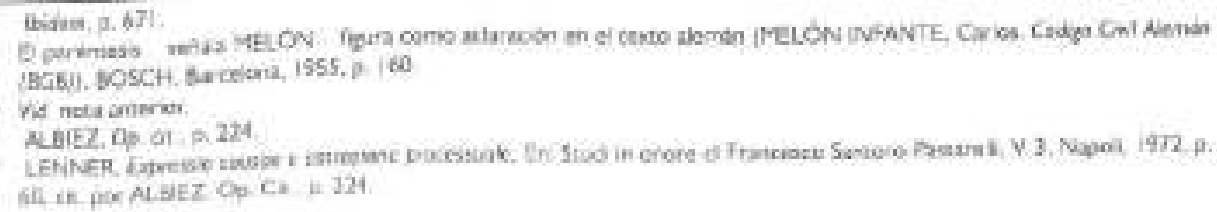


de lo cuai se hace por declarocián uno promeso de pogo o un reconocintiento de deuda, queda dispensade de probor la reioción fundomentol, cuys existencio re presume". Como se puede apreciar, el logisfador peruano, al igual que su par italieno, tambión optó por ubicar esta norma dentra de la Sección raferida a la promesa uniateral, también las agrupo en un mismo articulo y tambión les exargó las mismes efectos, pero en Perú, a dferencia de lo ocurrido en ltalia, la doctrina nacional no ha realizado el mis mivimo cuestionamiento a esta normi, por el contrario, se he surrido en el más profundo silencio. Tal situación nos obliza a expresar a'gunos comentarios soben los aspectos aytes indicados.

\section{v. NATURALEZA JURIDICA}

Uno de los ternas que ha despertado áperas y escabresas discusiones an la doctrina respecto de ambas declaraciones esta. referido a su naturaleza juridiea, La discusión se eentira baisicamertite en determinar: (1) Si son declaraciores de ciencia o de volumtad; (ii) Si son declaraciones caussics o abstractas; y (iii) Si son unilstersies o belateraies. A consinuseión abordaremos cada uno de estos aspectes de manera independiente.

Sin embargo, antes de iniciar el andi isis propuesto consideramos necesario conocer la intención que tuva of legislador italiano al regular estos institutos. En razón a ello, pasamos a clar un extracto de la felazione Ministeriale del Codice de 1942, respecte del artículo $19 a 8$ que regula ambas declaraciones:

"En el articulo 1988 se encuentran contenidos la promesa de pogo y el reconocimiento de deuda, presentodas como angacios unilaterales. El artieuio en referencia partir del hecho de que ambas dexiaracionss no hocen menciôn a fa reiación fundarnertital a la que se nefieren. $\mathrm{El}$ articulo 1958 atribuye prima focie o ambos virtiod abligctorie en el sentido que el deudar puede ser emplozodo en base a la promeso y al reconocimiento nin que sea necesario probar tambien ía relocidin findomental. Camo se ha dicha, serd de competencia del empibzado solicitar a prober lo faice de io reíación fundoriental empleando todas las defersas posibles.

Ei cosso merecio ser considevado porque es la sola promesa obligatonis ne titulada, y porque canenia panes en evidencia - mojor de cuanto resultó pora la promesa de pogo ef anicuío 1325 del Codjo de 1865 - que promesa de pago y reconocimiento de druda ne sen r no.

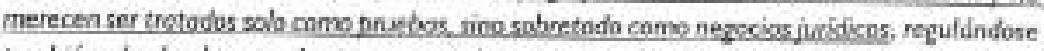
tombién, desde el punto de vista procesal, fa obstracción de lo reboción fundamentel, que siempre constituge une abstracción procesal y no moterial.

Lo falte de cavas es recardada en el orticulo $14 J 8$ cap. De esto resuita confirmadi lo

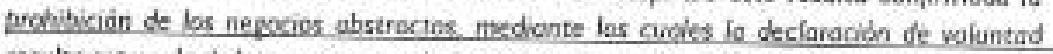

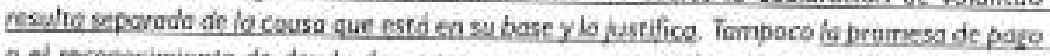

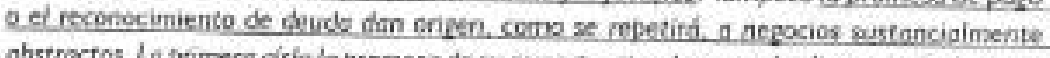

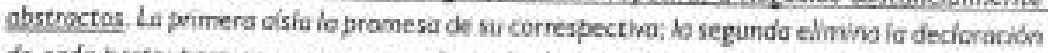
de cado partej pera en un case y en el acro la declaroción na es definitivamente fija par to rarin juridica, que in to determinudo. Ello es tan cierto que en ef mismo juicio en ef que la cantraporte hoce valer la promesa o el reconocimenta, el promitente o el declarante san odniodos a prebor la insubsistencie de ia reiacion fundaraental a su decaimiento, en mode gue el fuez se encuentra consureabido a conshair el complejo nepocio. de lo cuaf to promesd o el reconocimiento es extraida (llamede abstracción prncesal)" " (El subrryindo es nuestro).

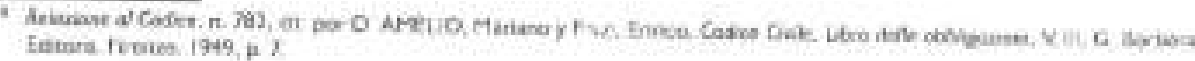


Dei parrafo trescrito se evidencla la intención dei legislador italiano de considerar a la promesa de paga y al reconocimiento de deuda como: (i) declaraciones uniaterales, (ii) negocios juridicos $(y$ no solo como pruebas); y (jii) declaraciones que no conssituyen negocios abstractos. En las siguentes lineas vemos a verificar si taies propósitos han podido concresarse.

\section{1. ¿Declaración de voluntad o deslaración de ciencia?}

De las múltiples contrewers as que han surgido sebre estas doclaraciones, la determinacón de si constituyen declaraciones de voluntad o de ciencia es la que más atención y discuasión ha generado. Para abordar este item, primaro vamos a decermirar lo que se debe entundar por decharacicon de voluntad y por declaración de ciencia, luego citaremos las principales posturas que se has esbozado, para firaimente precisar las diferenc as que existe entre el recanocimiento de dauda $y$ seras figuras afines.

Señala Galgano que los actos o declaraciones de volumtadt " (..) se distinguen, de entre lo vasta cotegario ste las hechas humanes. por el popel especifico que la woluntad humara desenvuefie en las mismos el efecto juridico constitutivo, modfícouvo a extintivo de las relociones juichcas no se enlazo son Ia sala valuntoriedad del cemportamiento humono sino con un aspecto uiteriar: Ia denominodo voluntad de las ofectos. No basta. corno si ocurre en el hecho humano en general, que el sujeto haye querida el hecho: aqui es necrsaria, povo que el efecto jurídico se produzco, que cl sujeto tombién hoyg querido el efecto" "io subrayaco er nuestro). Mediante la declaración de voluntad (también llamada doclaración negocial) se crea una relación juridica nueva, y en caso esta declaración haga referencia a una relación anterior, esta serdi distinta de aquela. En la legslación peruara, la doclaración de voluritad ha sido regulacta en el articulo 140 del Codige Clvilla, corstiuryendo una de sus especies. y. por cierto, la más representativa, al contrato (cuya definción ha sido reccoida en el articulo I35) del acotado eddigo"l).

De ocro lado, Gecuvo, refiriendose a las docharaciones de cienca, seiala que "(.., con estor,

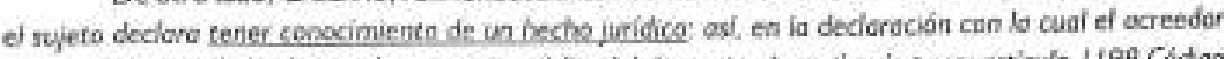
declora haber recibido el pogo de su propio credito fel denominado recibo de potgo: articulo 1199 Códgo Covil), o en la confesión, que es una deciaración de bechas desfavorabies para uno, y fovarables para otro farticilo 2730 Código Conip. ${ }^{2}$ El efecto de fas deciaracianes de ciencia na es, camo en el cosa de las decionocienes de volintad, el de canstituir modficar o extinguir refaciones juridicas, sino ef de brabat

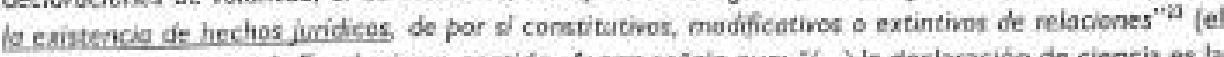
subrayado es nivestro). En el mismo sentido. Alarez saflala que: "(..) la declaración de ciencia es ta aseveración de unes hechos que pueden ser dados a conocer por terceros (declaración tésalfical) o por uno mismo (confesión extrajudicial), según sea la relación de los sujetos con los hechas. Cuardo perjudica al propio declarante se habla de declasación contro se pronuntiatio, y si se tiene por objoto derechos de declaración es deneminada come reconocimiento t" ${ }^{-19}$ Como se puede apreciar de las citas traseritas, la importancla de la declaración de cencia radica fundamentaimente en servir como un medio probatorio que acredita un datorminado hecho del cual el declarante tiene conocimiento.

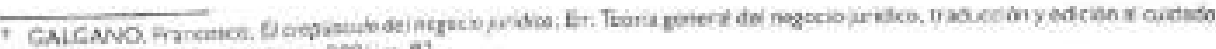

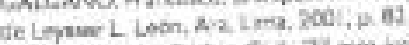

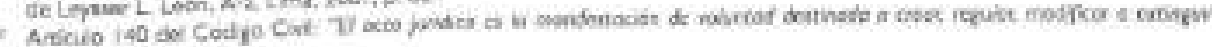
relacietes jerihtidi I"

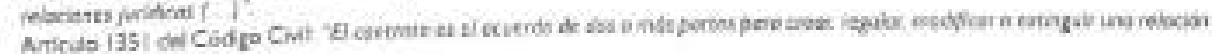

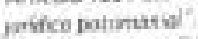

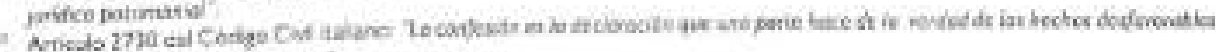
Dello y fosmatra a le vira pirte

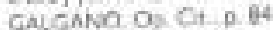

- AEER Op CI p.t3 
Una vez conocidos los aleances de anbas clases de declaraciones corresponde ubicar a ia promesa de pago y al reconocimiento de deida dentro de una de estas. Para ello vamos a anaizar la finalidad cue se persigue con cada una de dichas declaraciones.

Mediante la promesa de pago un sujeto se obliga frence a otro a cumplir una determinada prestación. Asli, euando una persona dice: "prometo pagarte" se está cornpromeciendo a cancelar una deuda a favor del destinatario de tal promean. Mediante esta declaración el promiterte quiere el acto y también quiere los efectos, como es pagar la deuda. Esta manifestacén de voluntad constituye un ejercicio de la sutonomia privada del sujeto, y es an virtud de esta, que le ctorga efectos negociales a su declaracion. Como se puede apreciar, la promesa de pago censtituye una declaración de voluntad.

Por su parte, rediarte el reconocimiento de deuda un sujeto "mirando hacia ol pacado" iv́entifica ura situdión juridica do deuda de la que él es titular $y$, seguidamente, la hace suya es decir. se la arribuye. En este caso, el sujeto constata algo que erz cierto, limintidose a afirmar una verdad. Eata dedlarseión no modifica una relación jurídica anter ker, solo reconoce alga que ya existia y de io caal él tenia conocimiento. Es como decir; "en la mañara lei un libro". Su función es la de probar la existoncia de una situación anterior, en este caso, de una deuxla anterior. Como se puede apreciar. el reconocimviento de deuda corstituye una declaración de clencia.

Considerar a la promesa de pago camo una declaración de voluntad y al reconocimiento de deuda como una declarscián de ciancia es la postura que la doctrina, casi unánimemence. scepca. ${ }^{\text {s }}$

Sin embargo existen ctres posiciones que no gozan de muchos adeptes, como, por ejemplo, k que sefrala que el reconoximiento de deuda puede vener distintas naturaleras de axuerdo a ia relación juridica precedonte $y \geq$ la finalidad de reforzar la posición del acreedor ante el deudor concediéndole una garantía para el cobro de su crédito, ${ }^{*}$ Otros autores, por su parte, han biscado un elemento en comuin a ambes daclaraciones corsiderando que tarto la promesa de pago y ef reconocimiento de deuda constitiyen declaracianes contes si, es decir, declaraciones que perjudicar a su emisor $y$ benefician al receptor. El beneficio para el receptor de tales declaraciones consistiria en que no tondra que probar el titulo bajo el cual es acrecdor." Siguiendo esta misma corriente, D Majo afirma que: "f ...) es el terreno probotocio aquel sobre el cual debe opreciorse la relevancia de fos deciaracianes a las que se refiere el enticifio 1988. Tompoca se debe habiar de presunciones legales yo que las declarociones del deudor contra si, por propia invinseca optitud demastrativa, san elevodas por la ley al rango de pruebas suficientes para lo existencio de ía deudo*:

No obstante las variadas concepciones que se han planteado en la doctrina, consideramos que ambas declaraciones tienen distinta naturaleza: por un lado, la promesa de pago constitupe una declaración de voluntad, mientras que el reconocimiento de deucta, una declaración de ciencia.

\subsection{Diferencia entre el reconocimiento de deuda $y$ el negozio di accercamento}

Se hapretendids encomtrer en el negazio of accertainsoto (negocio de fijacion o de constatación) la naturaleza juridica del reconocimiento do deuda. Mediante el negozie di accentemento se bustca determinar un elemento de hẹcho yfo de derecho de cuya existencia o extensión se dudaba, raxón por

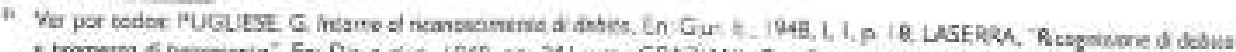

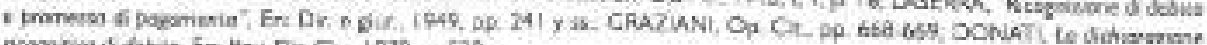
nowprowo is dobse, En Hev Dr. Crs, 1979 a 528

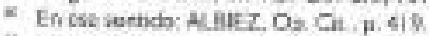

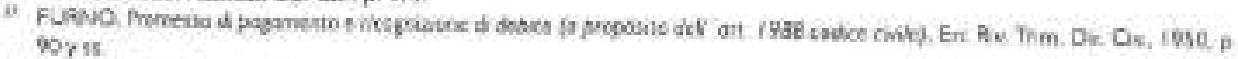

- CA Mapo Op Ot.p 1 m 
la cual tal situación de incertidumbre es susceptible oe generar confictus entre las partes. Justamenta para evitar el surginiento de tales conflictos es que las partes celebran este negeio. Como se puedo apreciar, en esta clase de negocio no se produce ninguna mutación juríica (ereación. rogulación, monificzción o extinción). Ejernplos de este tipo de regocio son, principaintente, la trarsacción y el reconocimiento de un hijo.

En nuestra opiniba, al reconocimiento de deuda no puade ser reconducido a un negazio di eccertamento, toda ver que este tiene una notabie diferencla cen la declaración de ciencia. En efecto, la declaración de ciencia presupone carteza juridica plera ea decir, no existe fucs o inexactitud de un hecho, corno sukede en el negazio di accertamento. Por medio de la declaración de ciencia se declarz una situación juridica que es cieraz, esto es, una verdad legal. Ello también ha

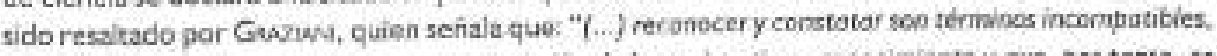
parrive el primero tiene por abjete una situación de la cual se tiene conocimiento y que, por tanta, es vierto; ef segundo, per ol contraria tiene par abjetn una situocibn que no se canoce con exoctitud y par eso se tiene incerteza subjetivamente o que, canociéndala, se quiere voiver abjectivamente cierta" "In

Para GRAZIANI, el recanceimiento de deuda no constituye una declaración de occertemento. sino de ciencia. Avnbos se distinguer en que: "I... ) ouando un sujeto quere superar ia incerteza subjetiva u abjetivo de una situcción juridica este occertare: en cambio, cuando se iimite e declarar lo existencioy d mado de ser de una determinada relación de fa cual es subjetivamente cierta, no es mds configurabie un aegecio de canstatación, sino una mera declarosibin de ciencia. $Y$ es esto dedarabión, precisamente. cquelía prevista par ef erticulo $1988^{\circ}$ ?

Esta distinción tiens una notable importancia príctica, ya que -como adverte Graziari"imientras en la deciarocián de ciencia previsto per el crticulo 1988 es posible la prueba cancrovia, equel que constats uno determinado reloción no puede evidentemente pretender la irexistencio o aducir hechos modficativos, extintims impedionos sinta saib impognar el negacio según las reglos peneraies. Resolio. por estos breves refiexoanes, í irredirctibilidad de las decionaciones cancemplados por el artíalo 1988 Q la actividad de constatación: el acto de reconocimiente en sontido propio no puede en algün moda ser considerodo coma negocio de conistotocián":?

\subsection{Diferencia entre el reconecimiento de deuda y el reconocimiento de obligaciones}

Un instituto con é que el reconocimiento de deada tiene cierta simalitud es el reconocimienno de cbligacianes. El reconcucimiento de deuda está regulado en al articulo 1958 del Cótizo Civili2, mientrus que al reconocimiento de obligaciones, en el articulo 1205 del Código Civi." Resaltando las diforencias entre ambcs institutos, Borda seciala que "(..) en lo promeso alsszacta de deudo no aparece lo ecrusu de la obligoción, pues le intención de las partes es precisamente no expresarla; io promeso es en si misnd lo fuente o titulo de la abfigución asumido par ef pramicente, El reconocimiento at deuda implica io existencia de une deuda enterior, que sirve de cousc ol nuevo octo". "34 Entonces, si la declaración hace referencia a un titula, estaremos frente a un reconocimianto do obligaciones (la obligación proviene del titulo que se ha reconocido); de otro lado, si al declarance no hace referencis a algún tifulo, estaremog frente a un raconoximiento de deuda abstracta, esto es, desprovisto de un titulo en qua se sustente cal toeclaración. Si esto es asi. entonces se podria ocultar tona doración

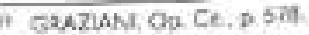

bitem 13 . 678

Whrt

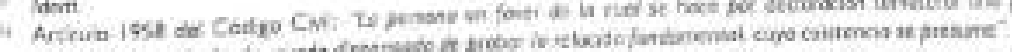

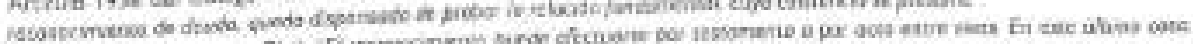

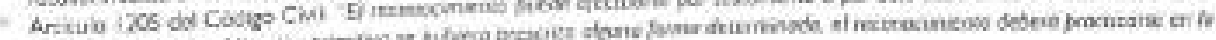

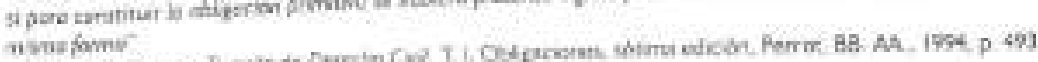

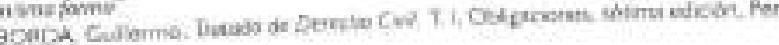


bajo la apariencia de un reconocimiento de deuda, pues basta con el reconocimiento para que surja, por efecto de la ley, la presunción de la existencia de la relación causal.

En conclusión, la obligación siprnpre tendrá un titulo en que se sustenta, ya sea cuando se haga referencla a il (reconocimiento de obligaciones) o cuando no (reconocimierzo de deuta), pues en este últ imo caso, por éncto del articulo 1988 deł Código Civii, su existenóa se presurne.

\section{2. iDsclaracien causal e abstracta]}

Otro sspecto de estas declaraciones que ha causado discusión an la doctrina está referido a determinar si estas constituyen declaraciones causales o abstractas. Por razcnes de espacio y porque no constituye el terma centrvi del preserte articulo, no trataremos a profundidad los negocios jiridices abstractos, ya que -a nuestro parecer- merecen ser abordados desde una perspectiva histórica y comparada. Sin embargo, ind caremas sus aspoctos esenciales y su diferencia con los negocios causales, para finalmente concluir en el tipo de negocio que constituyen la promesa de pago y el reconocimianto de deuda. Veamos.

Diez-Picazo considera que los contratos causales se presentan cuando "(...) io existencio y la licitud de lo couse opero como un presubuesta de la valider $y$ de lo efieacia del contrata. $5 \mathrm{H}$ lo causa no existe a es iicita, el contrato es nula $y$ por consiguiente, no puede reciamorse la prometido en virtud del cantratb y puede repetirse lo que conno consecuencia dei contrato se hojo dado" is En este caso, el negocio juridico celebrado poe las partes está intimamente viceulado a su causa, por allo. cualquier defecto o deficiencia en esta perjudica a aquel. En ei mismo sentido afirma Roppo: -Ei prinejpio de íc couso tutela a quien decloro io voluntad de obligarse, ofreciéredale un argumento pera poner en discutión lo promesa o ía atribución, $y$ exi, liberase de la collipacián: invocar el defecto de cousa. for ello misma ef pnncipio de la cousa piede perjudicar a quien cuenta cen las efectos legales de lo declaración cjena, $y$ en particular les terceras que han adquirido derechos dependientos de uno precedente estipuiación", Para graficar tal concepción, Roppo propone el siguianto ejemplo: "A dispone de un derecho of favor de $\mathrm{B}$, quien después io transfiere a $\mathrm{X}$ : si la atribución de $\mathrm{A}$ a $\mathrm{B}$ fuese privada de cause fo nulidad inducida par el prinoipio coussalisto afectovio tambièn la adquisicián de X. quien no sería ofectodo si reginio el principis de irrelencencia de fo causa" th

Ahora bien, respecto del negocio juridico abatracto, Diez-Picazo lo deline como " (...) el negocio juridico que oparece desilgodo e independizodo de su "couse", es decir, in contrato que funciono con compietri independencia de su causa. obstrocción hecha -de aqui su nombre: abatracto- dé cuál seo su crusa". Asimismo, el autor espatiol señala que la creación de la categoria de contratos abstractos "(..) constituye un intento de independizar ef efecto juricico de las pasibles ricisitudes. anomelios o irveguiaridades de que pueda odaiccer el iter cantractual causante de este efecta se trato, en definitian, de que el efecto jurílico se produzco a pesar de estas itregularidades, anomelias o vicisitudes y que ef destinatonio o beneficiorio def efecto juridica oo tengo que contar con eños o se wo afectado por ellas", anadiendo finalmente que "(...) el llamodo contrata abstrocto no es ung simple extelequio o un juego de conceptas. sino ef eji cardinai de toda una manera de concebir ei tráfico juridico fundodo sobre uno idea de seguridod". "Como se puede apreveiar, en este negocio. a diferencia del anterior, como quiera que la preocupación se centra on la seguridad del trafice juridico sa tutela al adquirsnta (o a los terceros\} ya que su dorecho no podrh verse afectado por algín defecto o deficiencia de la causa.

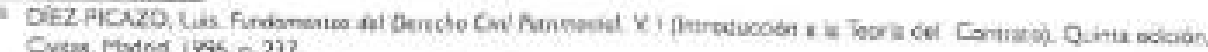

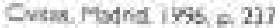

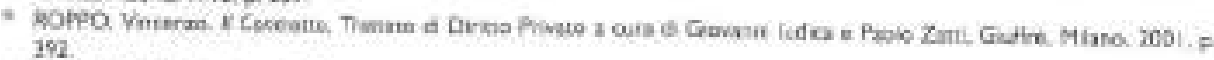

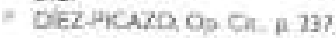


Sistemas juridicos que adoptan el Principio de ia abstrocción son fundamencalmence el alemdn y el suizo, mientras que casi todes los erdenamientos que adoptan el Principio de la couse son los que pertenecen al sistema romanista. En el primer sistema es posible la medstencla de contracos abstractos, mientras que en el sagundo, no.

Ahora corresponde decerminar ai la promesa de pago y el reconocimiento de deuda son negocios causales o si son más bien negacios abstractos. Cons deramos que para responder esta pregunta no basta apreciar el texto del articulo en el que han sido regulados, sino es importante analizar el contexto en que se deservoelven y el sistema acogido por el ondenamiento juridico en donde se encuentran regulados. En atención a ello, no compertimos la opinión de quienes alirman categóricamente qua tanto la promesa de prgo como el reconocimiento de deuda conscituyen per se dos especies del género contratos abstractos."

Pues bien, tomando en euenta que el ordenamiento juridico perueno adopta un sibtema causalista, no es posible la existencia de contratos abstractor. En efocto, en el ferù se ha considerado importarte tutelar al transferente del derecho, por ello se exige que todos los centrates tengan una causa (aunque no lo indiquen expresamente). Para corroborar tal situación basta char el articulo 140 del Cód go Civi en donde se establece como requisto de validez el fin lícite. "El fin no es otra cosa que la causa del negocio juridico. Como se puede apreciar, la norma no solo exige la existencia de la causa, sino además que esta sea forta. Nuestra posición encuentra respajdo ademis en la Exposición de Motivos del Código Civil, que sañala " ${ }^{-}($.$) no se trate de crear un acto abstracto sino de establecer$ que la decianción unibterol serd consideroda valida en tanto que el deudor no acredite la inenstencia de lo refación findamentaf", "*n consecuencia. la promesa do pago y el reconocimiento de deuda constituyen dedaraoienes eauales.

Es importante hacer notar la diferencia que una aterna doctrina espantola ha realizado sobre la presunción de causa $y$ ta abstracción de causa. La diferencia prística -según Abiez-censiste en que "(..) Medlante ía tecrio de la cbstracción de causa la validez y eficacio del negocio juridico no depericen de las vicisitudes de la relación juridica precedente, es decic que el negacio juridico estd abstraido de io cause, de ahi su nambre. Y solo concede a la parte perjudicado unas occianes llamados de enriquecimiento injusto. La prenunción de cousa, por el contrano, no otorgu eata proteccidin ol negocio juridico que tenga ss cousa en otro onterior. Solo produce una presumcido a fanor del ecreedar de que hoy ctusa y que esto no es coúmcla. Depende ya del deudor destruir esta oparienció creada a favor daf ocrecdor", "El citado autor que, tal vex por su origen alemin ha estudiado a profundidad el negocio abstracto y sus diferencias con otres inatitutos, finalmerte senala que " $(.$.$) La presuncion de caua$ permite, par un lado, to as expresión de la cousa en ios controtos, F. por atro. dispensa ol acreedor de

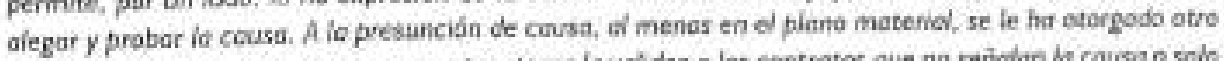
papel, que no siempre se tiene en cuenta. otorga la vahidez a las controtos que no serīolan ha causa o scio la indican de una forme generica" tz

De ello, resulta evidente que en el ardenamiento juridico pervano no se ha optado por la atstrzcción de la cousa, sino solo por la presunción de causa pues es posibla que el deudor demuestre que no existe una causa o relación fundarnernal en virtud de la cual ostenta la calidad de deudor.

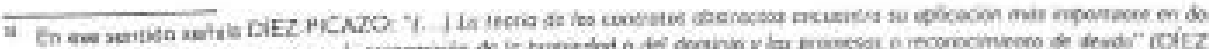

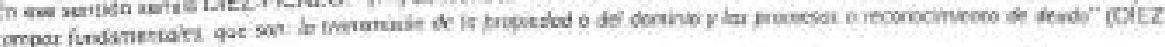
Pick. $20 \mathrm{O}, \mathrm{Cr}, 2.25$

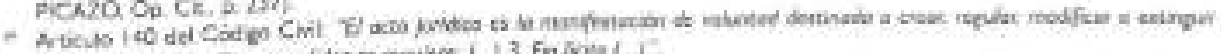

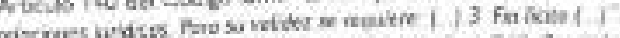

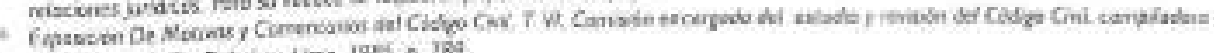

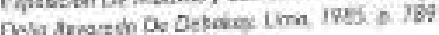

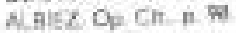

Bidem. 0.21 


\section{3. ¿Actos unilaterales o bilateraies!}

Como últirto teme respecto de la naturaleza juridica de la promesa de pago y de: reconocimiento de deuda cocresponde analizar ni las mismas constituyen declaraciones unilaterales o bilaterales. Para elo, vamos a definir el propósito de ambas figuras:

Como ya hemes serialodo, a través de ostas dedaraciones el deudor efectía una cantra se pronuntiotio reconociendo una deuda o prometiende sa pago. Tal declaración tane como efecto lberar al acreedor de probar la existencis de la relación por la cual ambos ostensan tales stuacioner jurícicas. Adtemb́s, una premesa de pago o un reconocimienco de decda que se corstituyan de manera bilateral iria en contra de la razón histórica que dio origen a estos institusos pues tome herros seisaludesuppr (num, 3), csmas declaraciones nacen para pocibilizar al acreedor hacer efectivo su derecha da erídito, haciendo surgir ura presunción de la exlstancia de la relación causal, sen la sola der lacación del deudor. Por alla, exigir la intervención del acreedor para que se produrzea tal efecto, ressaria utilidad a esta fattispecie. De ello se desprende que ambos institutos surten electos por la simple manifestación de valuntad de una de las partes fla cue reconoce la deuca o la que promete ef pago).

En el mismo sertido. opina la mayor parte de la doctrina. "Por ejemplo, Grazian safiala que: "(...) It expresión "reconocimiento controctud" es conceptugimente cantradictario si se andizd can atenoib́n el significada. Tá controdiccián se aprecio fundomentalmente con referencia a fa distinción

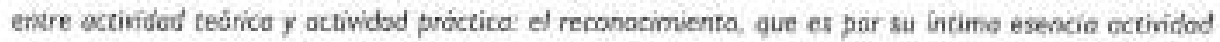
teórico, no encoje en el esquena del controto, acto de valuntad $x$ por cansiguiente, acto podecico. En otras zérmines, recanocer un derecho gjeno sigovice odmitit, atester, decíarar: por ejeraplo, que fizio es ocreedor de uno cierto suma; en tai meda el autor del recanacimienta valorw la reafídod y, en consecuencia. expresa un juicio"+4 Por su parte. D. Majo, refiriendose al articulo 1132 del Code que uriliza el término "corvvención", afirma que tai expresiōn no debe generar confusión, " $($...) dindo que ella sevialo sustancialmente un documento que conternga uno deciaración unileteral que indica o reconoce ung raxán

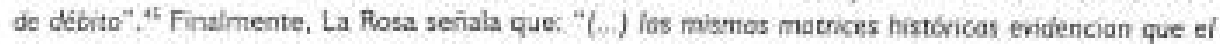
reconocimiento de derechas es an acto unilater don efectos meramente probotories, $y$ no tiene nada que

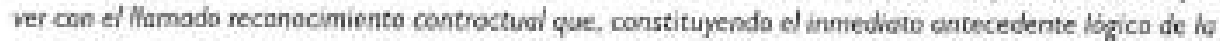
tronsactio y de la constatacion, serio más correctamente definido carro nezacio de constotoción" " -

No obstante to expuesto, debemes indicar qun estos institutes san censiderados como contratos en la legislación alemana, conforme lo serisłan los parágrafos 780 y 781 del BCB, trenseritos supro \{num. $M$,

\section{LA PROMESA DE PAGO Y EL RECONOCIMIENTO DE DEUDA EN EL CÓDIGO CIVIL PERUANO}

Luego de haber sealizade un analisis sebre la naturaleza juridica de las declaraciones objeto de estudia, cerresponde zhora sometar a examen ba forma en que el legislador penuano las ha regulado. Para elo analizarenos los siguientas aspectos (i) La regulación en un mismo articulo de ambas declaracioness, (ii) La inclusión de este articulo derkro de la sección referida a las promesas urilaterales, (iii) Ln naturaieza de la pressunción de la relación funcdamental, y (iv) E alecto de la prestinción do bexistencia de la relacion fundamental.

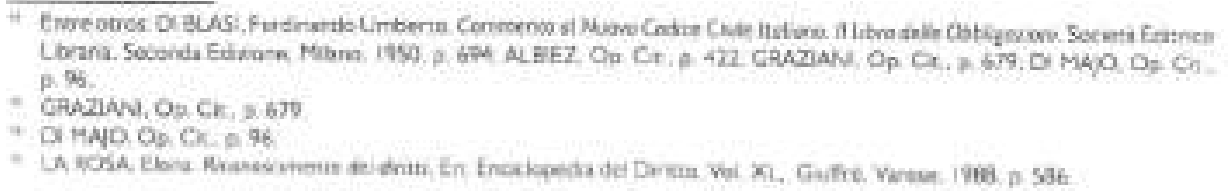




\section{LEs correcto regular a la promesa de pago y al reconocimiento de deuda en un mismo articulo?}

La promesa de pago es una declaración de veluntad, mientras que al recanocimiento de deuca es una declarseión de ciencia. Por elo, consideranos quo no es acertado incluirlas en un mismo articulo, y muehe menos, ocorgarles los mismos efectes Asi también senala. Aibrez:"(-) puede resiltar un poco chocante que lo pramesa de papa sea una institivión of in al reconocimiento de deudo.

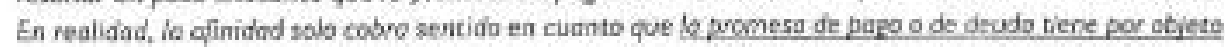
ung abiggocian antenior. Fuerd de este supuesto la promesa despoiege una eficacia propia y distinta o un reconocimiento de deuda " "Avade ei citado autor alemán, que "( - ) la promese de deudo encierra uno vaísntad de mads alcance que une valuntad confesurio. La valuntad de promieter contiene un propósito que no es salo el de hacer constatur uro abligeción anteriox, sine el de creat un vinculo jurifico navewa De ahi que no tiene sentido ver en la promesa un acto de noturnieza prabataria. El propio Tribune' Supremo en varios sentencias seniala que lo prameso de paga a ite deuda es resultado de un deliberado propósito de cumplimienta. Ella no excluye que a meces ia pramesa se pressa cen la inica finelídod de prabar la deuda. Pers en este caso mis que de promesas se thato de reconocimientas cue aseveren lo exiscencie de una deuda"* (el subrayado es nuestro).

Enel mismo sentido, sefiala Di BL.as: "Teüricomente bo sidb oufvertido la distinción encre fromesa de paga y reconocimienta de ctudo. Le prarnesa es un negucio dispositivo (o canstitutivo), destinado a oreor una nueva reloción juridico que sustitupe a lo precedente, se constituye a su loda mientras que el reconocimiento tene, respecto o la refocián precedente, salo naturaiezo declorativa, vaie décie tiende a consideror ieguro su enstencia" a

Como quiera que el mismo errer ha comotido el legislador italiano, ia doctrima iraliaa ha parteado los posibles motivos que pudieron causar tal imorecisión legislativa. Asi, por ejemplo, Baudry-Lucantinerle y Barde han serialado que: "f. J el problemu ha sido ofrontodo por los intérpretes del artículo / 132 del Code, quienes, a propósito de les declonociones del spo je pranets paper o je recanois deroit, habion habloda de "mariantea, que o menuvo se han debrido a un casa de redacción, y

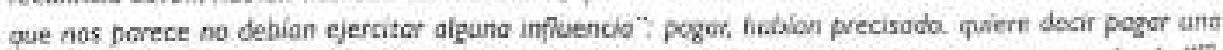
deuda, "prometo pogor quiere decir prameter pogor una cluda, y, por lo tento, reconocer ser deuder" Esto nos demuestra que fue a pertir de franciv en donde se camsenab a identificer a ambes dechavaciones

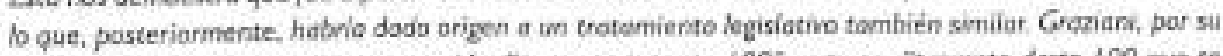
parte, reakizo un razonamiento parecida "prometo pogarte 100 ; esta es, Prameto darte 100 que te debo", o seo "recrnozko deberte 100 y prameto pogdrtelas". "II El termino "prometer pagar" llevaria implicito el recanoximiento de la deuda, razón por la cual el legislador italiano las habria regulado en un mismo articulo.

S. irterpretarios de manera literal ambas decharaciones podriamos acribar a estas distinas conclusiones: (i) Una diferenciz entre la promesa de pago y é reconecimiento de desta es que éste solo reconoce ser deudor, nas no se campromote a pagar la deuda reconocids; mientras que en la promesa de pogo el promitente promete pagar su deuda (fo que ya implica uns reconocimiento) y (ii) Si recanozco algo es porque quiero asumir los efectos de tal reconocimiento, entonces si reconozco una deuda, es porque quiero asumir los efectes de la deuda, como en ol do pagarla. Reparese que las interpretaciones realizadas se sustentan en ta voluncariedad de quien emite la declaración, sin

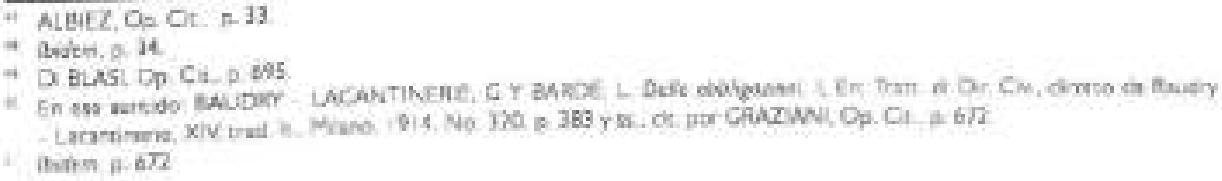


embargo debemos resahar que elio no tiene importancia en el plano juridico, toda vax que el hecho de querer o no cumple es indiferente para el Derecho, basta qua se haya corstituido la obligación para que la misma pueda ser exiģle jurídicamente.

Finalmerte, es necesario precsar cue en la doctnina alemana, tal vez por la forma en que se regulan a ambos institutos, se las consideran similares. Asi por ejemplo, Enneccerus senala que: "el reconocimiento de deuda es a la vez una promesa de devda" añadiendo que "ombos cantratos san solo farmas distintes de la promeso abstracto de prestocidon, par lo cual el Códipo Civil alemdin las samete a les mismas negias" ${ }^{23}$ por su parte, Von Thur opina que "Es perfectamente iguel que se escriba "prometo 100 o $X^{\prime \prime}$ que se escriba "recanazco que debo 100 a X" si Es importante hacer nocar que las dóterencias que se basan en la regulación legal no son miyy ùtiles, mis zủn cuando la ragulación alemana es distinta a la peruana.

\section{Cla promesa de pago y el reconocimiento de deuda son en realidad promesas unilaterales?}

El articulo 1958 establece una presunción de la existencia de la relación fundarrental, que opera cuando unz persona promote al pago o reconoce una deuda. Como se puede apreciar, la obilgación no surge por taber reailizado una promesa unilateral, sino por la presunción de la existencia de la relación fundamental. En éfecto, cuando alguien promete pogar, estí diciendo que cumplirzi una prestación que está pendiente de ser ejecutada, y tal prestación proviene de una causa que la origina. Similar situnción se presenta coc el roconocimiento de deuda. en donde al meconocerse cue se debe, se estí confirmando algo que existe $y$ esa deuda también tiene una causa que la originó.

Por ollo, considerames que darticulo 1958 del Códige Civil camete el errof se corsiderar a la promesa de pago y al reconocimiento de deuda como promesas unlaserales, toda vez que la "promess" o el "reconocimiento" no son los que producen la oblgacion, como ocurre (o debe ocurtir) en las promesas unilaterales, sino qua la obligación se produce per la relación caisal que está siendo reconocda $\odot$ por la cual se está prometiendo di pago. Por lo tanto, ambos supuestos no son tícnicamente promesas unilaterajes.

En d mismo sentide opina Abahdejo: " \% - ) no se trata de unà declaración de obfigarse a ellb, sina de que habla un recanocimiento de quien debiensjo olgo desde ontes, deciarabis deberio, y se camprametía

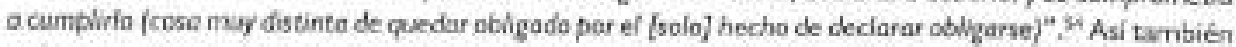
se ha prontrociado Sacco: "(. I la promesa ebseracta de poga, asi camo el reconocimiento de deuda se opopon sobve une preexistente fuente de cbligociones (y entances la obligoción derivaró de taf fivente). a tel fiente faita, y entonces la pramesa ubstracto (asi como el recanocimiento) no serviró para crear la abilgoción produciondo simplemente, sobre el piano procesat, una inversion de ia congo de fa pruebo" "ss La jurisprudancia italiona, compartiendo tal posición, seriala que " $($, , ) La promesa de pago tiene vior meramente confirmativo de una preexistente relacián fundamental, pero no ex idänen pare saristituir nuevos obligocianes" it En el mismo sentido Bigiazzi et af seriala que el Codigo Civil ital ano roguia

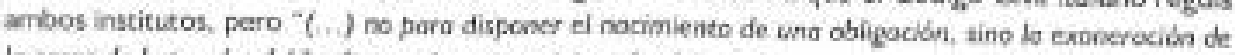
la carga de la proeba dei becho on ef que se arigina el crédita" "z

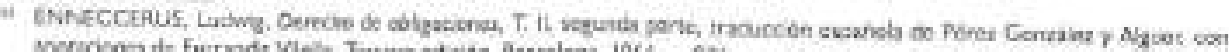

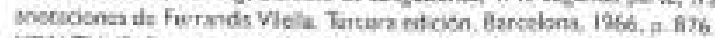

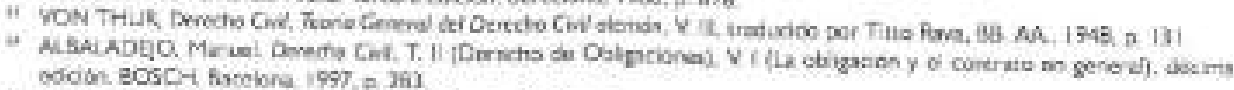

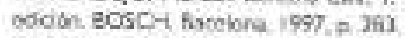

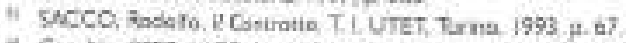

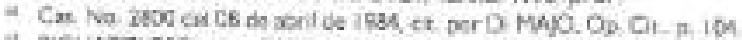

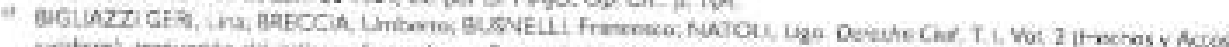

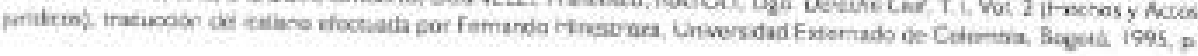


Es rriss, nusstra posición no solo tiene sustento en autorizadas doctrinss extrajeras, sino tambièn en la Exposición de Mosivos de nuestro Código Civil. En efecto, dietro documento tambièn pone de reliewe que la fuente de la obligación no es la promesa urilateral, sino la relación antecier existente entre promirente y promisario. Pare corroborar ello, pasamos a transcribir uno de sus párrafos: "La relacián fundamentel o que hoce referencia este articulo es la reloción juridico petrimonial existente entre el emisar de la deciardeión inilateral y el destinatario de la misma en virtud de fa cuer se hace lo proneso de pogo o el recanecimento de deuola. Esen malibad ia razón de la deuda: ello justifica do

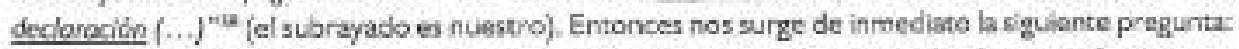
si nuestro legsiador en consiente que "en realidad" lo que genaraba la deuda no era la promesa sino la relación fundamental, kpor qué reguló ostas declaraciones como promosas unilaterales? La pregurta surge de inmediato, mas no asi la respuesta.

Consideramos que el error incurrido por el legisiador peruano es consecuencia de "importar" normas foriness (el articulo 1988 del Codice) sin ol debido analisis previo y, lo que es peor aûn, sin atender a las criticas que la doctrina inaliana expresaba sobre esta norma. Ast, por ejemplo, respecto de la ubicación del articulo 1988 del Codice, Graziani seîalaba que "( ..) parecia corente de sentido ilasertorla enve las proniesos unilaterales: el hugar mós correcto ero, evidentemente. aquel reíativo a los pruebas, camo establecio el proyecto prellminar del libro de les obligaciones't, 19

Asimismo, intentando encentrar uns razón parz este desscierte del logjsiador itaĭano, Gewwa sentala que "(..) es praboble que lo refecencic a la "promeso" de pogo pueda haber inducido al iegislodar a

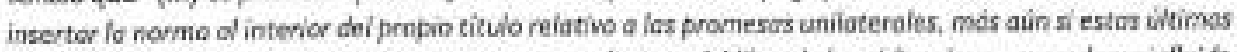

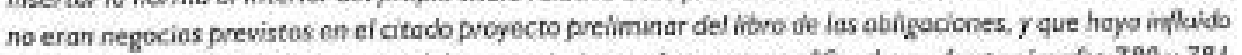
el modela alemain de la pramesu y del recanocimiento abstrectes codfficodas en ics parbogrofos 780 y 781 del BGB. Es significatives que la Relazions al código in. 782) afirmo que promesa de paga y recanocimiento de dewda han sido reunidas en cusonto opayecen como rogocias unilateroles" so

Finalmente, debamos señalar que si al icgislador penuano quiso otorgar efectos sbligaronos a la sola promesa de pago e al roconocimiento de deuda, no se debio referir a la presunción de la existencia de la relación fundamental, sino hubiese incicado simpiemence que la sola promesa de pago o el reconocimiento de deuda generan una obligación.

\section{Naturaleza de la presunción de la relación fundamental}

El efecto que otorga el articulo 1958 del Código Cive a la promesa de paga y al reconocimiento de deada cs la presunción de la existencia de la rehación causal o fundamental. Sin ambargo dictio articulo no indica cual es la naturajeza de dicha presunción, es decir, no precisa si se trata de una presursción duris tatum o aure et de iure." Cormo quiera que no existe un articulo que nos indique córno identificar la clase de prasunción que contene una norma (como si sucede para identifar la clase de formalidad, de acueroo al articulo 144 del Codgo Civilith , consideramos que para resclver

677.

is Erwosicile de Maimar, Op. CK, Tas

" Geazlans Oo Citi i 6ri.

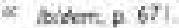

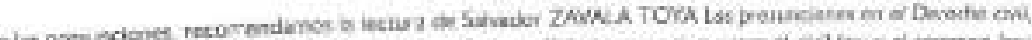

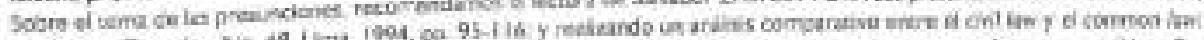

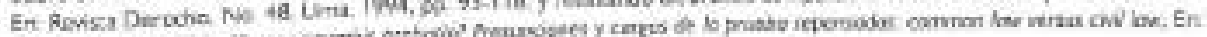

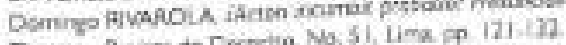

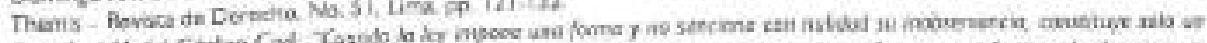

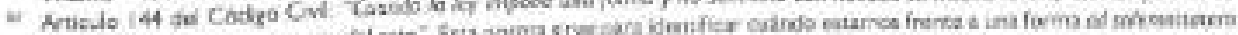

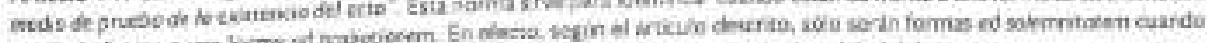

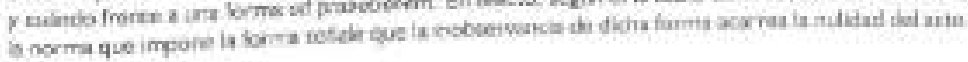


dicho probiama es necesario identificar el interds que of iegislador ha protendido tugetar al establecer dicha presunción.

Asi. é electo principsl de esta presunciôn es liberar al promisario de la carga de probar la existencia de la relación fundartental, es decir, mediante esta presuinción se inviarte la carga de la prueba a favor del promiszro. Elo evidencia que esta prosunción asta hecha en beneficie del promisario, por lo que cornsideramos que la presunción es turis tantum, pues se debe permitir a quien lo beneficia (promisario) la prueba en contrabla, en caso no sanga interés en ser acreedor. Por cemis, como senalan Di Majo", Gazzon" "y Gazlani", asi ha sido reconocida por la doctrina y jurisprudencia italanas."t

Nuestra interprotación tambian tiane rospal de en sede nacioral, toda vez que el Articulo 2010 del Proyecto de la Comisión Rewsora, eue reprodujo integramente el articulo 3 dal Anteprojecte presentado por el Dr. Manuel De La Puente y Lavalle ante la Comisión Reformadera en junio de 1981, sehalaba que: "To persone en fovor ofe if cual se hoce par declaración unilaterol unv promesa de pogo o uh recanociniento de deuda, quedo dispenstda de probar ia reiación fundamental, cupo existencia

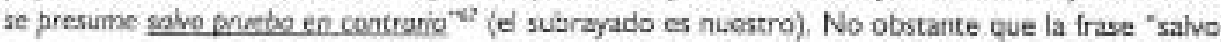
prueba en contraria" ha sido suprimida por la Comisión Revisora", es evidente la "intención de legislador"ws en incorporar expresamente ura presunción iuris tantum.

\section{Efecto de la presunción de la existencia de la relación fundamental}

El efocto fundamental que produce ta presunción de la existencia de la relación fundamental os liberar al promisario de la carga de probar el thitulo bajo el cual ostenta la situacion jurídica acroedora. En el momento en que se realiza la promesa de pago o el roconocimiento de deuda. por afocto de ia norma. se produce una presuncián de la existencia de la relación fundamental que dio origan, justamente, a la obligación que ahora está siendo reconocida o cuyo pago se está promediendo.

Respecto del articulo 1988 (que, como hemos sefialado, es ol antocedente de nuestro artícula 1958), Messitieo, respaldindose on la Ficlozione, sentala que: "La ley (articulo /988) cuando dispone que lo existencia de ie refación fundaniental se presiane mientros no hoya prueba en contrario, despiaza la cargo de í pruebo, echando ta prueba de fa eventud inexistencia de la relación findamental, sobre aquel que ho hecho if promesa de pogo, o el meconacimiento de la deudla; esto es, cree in caso de negocio

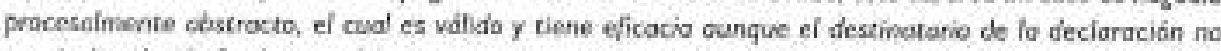
pruebe ia reibción fundomental; Ja decloración deja de ser vơlida, solomente en cuanto quien está obligacb a bose def negocio hryo de probor, y consiga probor, la inexistencie de ese misma relación fundamencaf'?

- DiMANO On Ce, o los

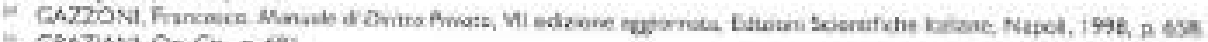

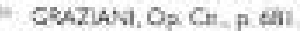

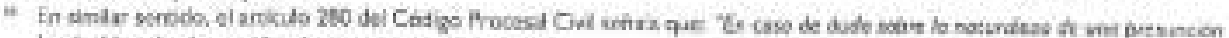

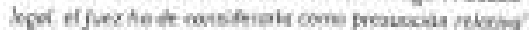

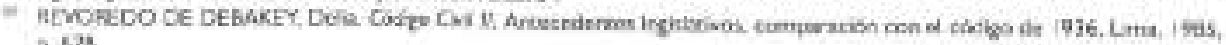
p.74.

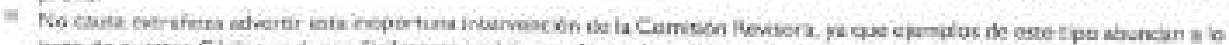

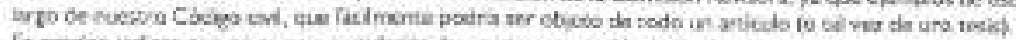

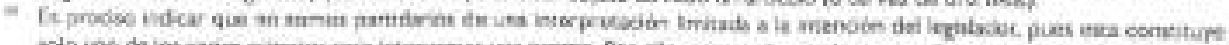

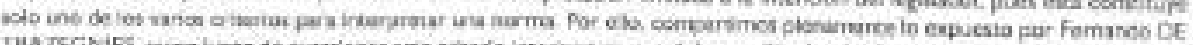

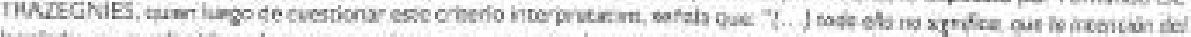

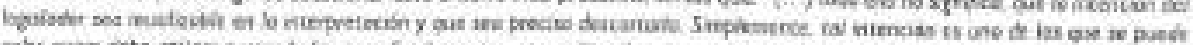

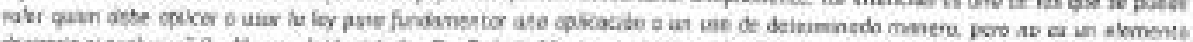

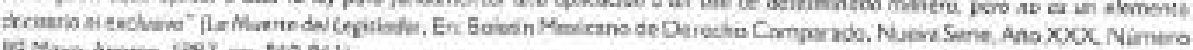

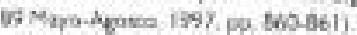

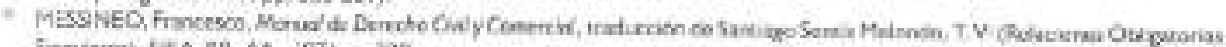

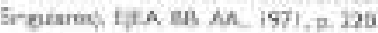


En ef misma sentido, Graziani sehala que las declaraciones de las que trata el articulo 1988 son contro se pronuntiationes y en cuanto tai, producon efectos cue trascienden sobre el nerreno precesal y en particular sobre aqual probatorio (en sentido tato)."

Por su parta, Albiez, rofiriéndose al articulo 1277 del Códgo civil español', seriela que: "Es una narma que cumpie dos firnciunes básieas: fundamentar la validez dei cantrato que no indíco la causo - el recanocimiento de deudo es el caso más cípico junto can la promesc ade pago-y dispensar al ocreedor de tener que probor lo couso de la obligoción ", "3

En sede nacional, en la Exposición de Motives del Codigo Civil se ha soñalado que: "f -.) el articula 1958 al decir que se presime lo existencio de ia reloción findamentol está simpiemente rrasladando al deudar lo cargo de la prueba de la existencia de tal relación, de tal manera que no si troto de crear un acte obstracto sino de establecer que lo decleracián uniloterd será cansideroda vaindo en tanto que ol deudior no ocredite la inexistencia de ta relocion fundomentar?"

En cenclusión, tenemos que la presuneión establecida en al articulo 1958 del Código Civi tiene un importante rol en el terreno probateria, pacs su función primordal es la inversión de la carga de la proeba. Por ello, sif el promitente roconoce una deuda o promete su pago, se presume que existe una relación fundamental que dio origen a dicha deuda. y sl luego el mismo promitente quiere retractarse, como señala Di Majoc "(...) tendrá que demoserar que dicho decloración la realizó por error de heche o par vialencia" is En efocto, las opeianes que tendria el promitente para evitar curnplir su abligación sería argumentar que la declaración per la cual manifestó su promesa pacieció de zlgún vicio de la valuntad, que el promisario no ha cumplido con su contraprestación o que fa obligación es lícita o inexistente.

\section{Posibles escenarios}

Si bien la persona que promete el paga o que reconoce la dedta constituye el sujeto pasivo de la relación obligatoria, es posible que la relación fundurnental hays orignado prestociones recipracas, y la prestación que correspende al destinatario de la declaración tampoco haja sido ejecutada (o lo haya sido solo de manera parcia), En tal caso, la persona que ha reconocide la deuda o ha prornertido su pago deberi probar su derecho de crédito, salvo que el destinatar io tambián reconozca o prometa el pago de su deuda, con lo que tendriamos dos "promesas unilaterales" que se refieran a una misma relación fundamerrial.

De otro lado, es pesible también que el deutor reconozca o promera el pago de una deuda pero solo partialmenta. Por ajernpio, si en virtud de una relación causal, A es desudor de B por S/.100.00, pero A solo reconoce una deuda de \$1.80,00. En esce caso, aplicando la presunción conterida en el articula 1958 del Código Civk, el acreedor no tendria que probar su derecho de cródito respecto de los $\$ 1.80 .00$, pero si respecto de loc $\$ .20 .00$ restantes, toda vez quela inversión de la carga de la prueba solo operaria respecto del monto reconocido ( $\$ 1,80.00)$.

\section{APOSTILLA}

A lo jargo del preserte articulo hemos podido apreciar źosso modo la evolución histórica y logislativa que han experimentado la promesa de pago y el reconocimionso de deuda hasta llagar a

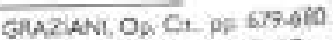

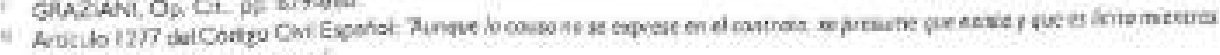

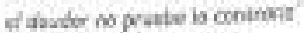

Nenitz, Op Ot.p. 2 il.

Eaposiods de Mouncos. Op Cr. a ras.

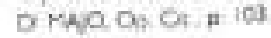


ser regulados en nuestro articulo 1958 del Codigo Cinl. De cillo hemos advertido que dicho articulo es el producto de ura irreflexiva importación legislativa que, larnentablemente, se hace cada vez mós comü en nuestro pais. Consideramos que la manera de regular z un determinado instituto juridico no debe depender de ordenamientos juridicos foráneos (por más "resperables" que estos sean). sino, por el contrario, la regulación debe estar en función a las necesidades que tiene una scciodad en un tiempo y espacio determinados.

Fimalmente, ahora que ya conocerros el escenario nebuloso y pantancso en el que se deserwuelve la Cenicienta del Derecho Civil, esperames que ela no desaliente su estudio, sino, por el contrano, invitamos a que muchos la visiten y también que b inviten a lis flestas. 